\title{
Efficacious Dendritic Cell Based Immunotherapy for Advanced Solid Tumors: Three Case Studies
}

\author{
Chandan R Bora ${ }^{1}$, Ileana Nordet Carrera ${ }^{2}$, Fidel S Rampersad ${ }^{3}$, Andrea M Richardson ${ }^{4}$ and Pramod S \\ Dhembare $^{* 1}$
}

\author{
${ }^{*}$ Corresponding authors \\ Pramod S Dhembare, Managing Director, NOVO Cellular Medicine Institute, \\ Fidelity Healthcare Ltd, 69 Robert Street Woodbrook Port of spain, Trinidad.
}

Submitted: 17 March2021;Accepted: 24 March 2021;Published: 07 Apr 2021

Citation: Chandan R Bora, Ileana Nordet Carrera, Fidel S Rampersad, Andrea M Richardson, Pramod S Dhembare (2021) Efficacious Dendritic Cell Based Immunotherapy for Advanced Solid Tumors: Three Case Studies. Medical \& Clinical Research 6(4): 495-503.

\begin{abstract}
Background and Aims: Dendritic cell (DC)-based immunotherapy is promising as a viable tool in cancer treatment. Dendritic cell (DC)-based vaccination can provoke antitumor $T$ cell responses in vivo. These case studies examined feasibility and outcome of DC-based tumor vaccination for patients with advanced cancers. This approach has been used mostly in patients in the presence of defined tumor antigens.
\end{abstract}

\begin{abstract}
Experimental Design: Accessible tumor tissue was disrupted into single cell suspensions. Autologous DCs were prepared from adherent peripheral blood mononuclear cells and cultured in granulocyte macrophage colony-stimulating factor, interleukin and autologous plasma. Tumor cells and DCs were co-cultured in the presence of polyethylene glycol to generate the fusions. Fusion cells were quantified by determining the percentage of cells that co-express tumor and DC markers. Patients were vaccinated with three doses of DC $\left(10 \mathrm{X} 10^{6}\right)$ were administered after every 2 weeks'intervals and assessed weekly for toxicity, and tumor response was assessed at 3 months after completion of vaccination.
\end{abstract}

Results: Vaccination was well tolerated. No physical signs of autoimmunity were detected. There was no evidence of significant toxicity from vaccine or adjuvant. There was increased expression of Thelper type 1 cytokines. Vaccination resulted in a significant reduction in the level of prostate-specific antigen (PSA) in the prostate cancer patient. Disease was stable upto 6 months in cases of breast and cervical cancer patients.

Conclusion: DC-based vaccination can stimulate an antitumoral T cell response in patients with various cancers. This data indicates that vaccination with autologous tumor-pulsed DCs generated from peripheral blood is safe and can induce tumorspecific cellular cytotoxicity. Clinical responses are achievable, even in patients with advanced disease.

Keywords: Dendritic Cell; Vaccination; Prostate Cancer; Immunotherapy; Prostate-Specific Antigen.

\section{Introduction}

Dendritic cells (DC) are one of the most potent Antigen presenting cells (APCS) of the immune system, and they have ability to stimulate T cells ${ }^{1}$. DC are the cells which capture proteins, digest them proteolytically, and then present the resulting peptides on its cell membranes bound to MHC antigens [1]. This complex of MHC-peptide is responsible for the activation of T cells. Apart from this, DC also has high levels of the costimulatory molecules, CD80 and CD86. This CD80 and CD8 led to the full T cell activation [1]. These DC are mostly found in various parts of the body like the epidermal layer of the skin, the respiratory and gastrointestinal systems, and the interstitial regions of several solid organs. These DC then acts as sentinels engulf invading microorganisms for presentation to immune cells [2]. In recent times DC-based cancer vaccines tested with some success in clinical trials with several types of cancers, such as Follicular-B cell lymphoma and melanoma [3-5].

$\mathrm{DC}$ are the most effective antigen presenting cell for activating CD8+ cytolytic T cells, CD4+ T cell help, and antibody responses [6]. Furthermore, most cancer vaccines require cross presentation of the administered antigen by DC [7]. We therefore hypothesized that vaccines based on DC loaded with tumor antigens would provide potent antitumor responses with low toxicity, precise specificity, and a sustained effect (due to immunologic memory). There are several possible sources of DC for immunotherapy Med Clin Res, $2021 \quad$ www.medclinres.org Volume 6| Issue 4|446 
strategies; DC may be generated in vitro from monocytoid precursors or $\mathrm{CD} 34+$ progenitors $[8,9]$.

Prostate cancer is considered the most leading cause of cancer death among males after lung cancer [10]. Majority of prostate cancer cases confined only to the prostate. Only few of them diagnosed locally advanced or metastatic prostate cancer. Many treatments like hormonal, chemotherapeutic and radiation are available for metastatic prostate cancer, but they are not able to show curative potential in these patients [11]. Similarly, breast cancer is the most frequently diagnosed life-threatening cancer and the leading cause of cancer death among women worldwide. It includes a mixed collection of diseases with various histologically defined subsets, clinical presentations, responses to treatment and outcomes. Even dermatologists also play important role in diagnosing such diseases [12]. Genital warts, as well as precancerous lesions and carcinomas of the cervix, vagina, and vulva, human papillomavirus (HPV) infections leads great morbidity and mortality in female. Currently many vaccinations are available for the prevention of cervical cancer and precancerous lesions. To lessen the burden of healthcare for cervical cancer, it is necessary to develop vaccination for the control and treatment of genital HPV [13].

Failure of primary treatments as in metastatic cases, there is huge demand for new and improved treatments for multiple cancers. Now a day, immunotherapeutic approaches to cancer management have shown promise in experimental studies, and a number of immunotherapies are now being tested in clinical trials as well. Our group has been developing a prostate cancer vaccine 'Dendritic cell infusion' as a vehicle to present prostate, breast and cervical antigens to $\mathrm{T}$ cells. Our case study in prostate, breast and cervical cancer with DC will be discussed in these case studies.

\section{Materials and Methods}

Written consent was obtained from each patients prior to the procedures. All protocols were followed by institutional safety guidelines. Pre-procedure investigations includes Prostate Specific Antigen (PSA), Renal Function, Liver Function, Lymphocyte Panel tests, Electrocardiogram (ECG), Computed Tomography, Ultrasound, Magnetic resonance Imaging (MRI) etc.

Generation of Monocyte derived DC Vaccination: Generation of $\mathrm{DC}$ vaccination was carried out as described by Bauer $\mathrm{C}$ et al (2011) with certain modification. Briefly peripheral blood mononuclear cells (PBMC) were isolated from $50 \mathrm{ml}$ whole blood of patient by Ficoll density gradient centrifugation (Hisep, Himedia). Isolated PBMCs was washed with certain times with PBS. PBMCs were incubated in culture dish $\left(\operatorname{Nunclon}^{\mathrm{TM}} \Delta\right.$ ) for $2 \mathrm{~h}$. Non adherence cells were removed and adherence cells were cultured with complete medium (autologous serum, Roswell Park Memorial Institute 1640 media (RPMI) with L-glutamine, Recombinant Human GM-CSF, Recombinant Human IL-4 and Gentamycin). Autologous serum was heat inactivated before use. Cells were replenished after alternate days. On 6th day cells were maturated with maturation stimuli (Polyinosinic: plycytidylic acid and TNF- $\alpha$ ).

Antigen priming with DCs: For antigen exposure, for prostate and cervical cancer recombinant protein was used and for breast cancer patient biopsy was used for antigen extraction. Protein concentration was estimated by Bradford reagent. After 5h of adding maturation stimuli, $25 \mathrm{ug} / \mathrm{ml}$ of recombinant protein was added. On 8th day antigen primed maturated dendritic cells were ready for infusion.

Quality control of DCs: Throughout the process cells were monitored under inverted microscope for any cross contamination. Before infusion cells were checked for bacterial contamination by gram staining. Bacterial endotoxin was determined by Pierce LAL Chromogenic Endotoxin Quantitation Kit (Thermo).

Dendritic cell infusion and follow up tests: Cell viability was performed by trypan blue exclusion staining. Three doses of DC (10 X 106) were administered after every 2 weeks of interval by IV along with $100 \mathrm{ml}$ saline as a slow infusion. Lymphocyte panel were evaluated before DC vaccination and after every infusion of every vaccination. Before and after every vaccination. PSA level was estimated in prostate patient. After 4 months of interval ultrasound of prostate were carried out.

\section{Results}

All 3 doses of vaccination were well tolerated. After every vaccination, blood samples were taken to check and verify the activation of lymphocytes by dendritic cells. Samples were sent to Quest laboratories USA. Results are summarized in Table 1, $2 \& 3$. Dose 0 is before treatment and dose 1,2, 3 are after every vaccination.

\section{Case 1: "Case Study on Prostate Cancer"}

A 84-year-old man was shown to have a prostate-specific antigen (PSA) level of $152.1 \mathrm{ng} / \mathrm{mL}$ in a routine evaluation. His physical exam was normal and the digital rectal examination revealed a slightly enlarged prostate. His past medical history was unremarkable. Laboratory data showed the following: Hemoglobin level $15 \mathrm{~g} / \mathrm{mL}$, hematocrit $3 \%$, white blood cell count (WBC) 3900 $\mathrm{mm} 3$, normal differential, platelets 258,000 , blood urea nitrogen 15 , creatinine 0.8 , and alkaline phosphatase $269 \mathrm{U} / \mathrm{L}$, increase AST, ALT in liver function tests.

\section{Case 2: "An Illustrated Case Study on Breast Cancer"}

$61 \mathrm{Y}$ female with a speculated irregular mass was discovered in her medial right breast (Figure 4). She acknowledged she was able to appreciate a palpable prominence in her medial breast and a "lump" in her right axilla. An ultrasound (Figure 5) disclosed a highly suspicious mass that measured $3.57 \mathrm{~cm} \times 3.89 \mathrm{~cm}$ in the breast, and enlarged lymph nodes noted within the right axilla, measuring $1.73 \mathrm{~cm}, 1.69 \mathrm{~cm}$ and $1.22 \mathrm{~cm}$ in diameter respectively... Based on patient's condition breast cancer, the surgeon felt she should be considered for neoadjuvant chemotherapy. Ideally, the patient would receive immediate systemic therapy, followed by an assessment of response to this therapy. If the patient then chose breast conservation, this plan would improve her chances and the ultimate cosmetic result. Patient was referred to a medical oncologist and DC vaccine therapy was chosen. She had a dramatic clinical response with resolution of all palpable disease.

Case 3: "An Illustrated Case Study on Cervical Cancer" 56 years' female presents for follow-up at Alexandra MRI. Patient complains of frequent vaginal bleeding, pain/discomfort upon urination, and lower back pain. She reports being hospitalized twice 
in the past few months for vaginal hemorrhage. MR appearances were consistent with an infiltrating, locally invasive, cervical neoplasm. This extends to involve the uterine body and fundus, the posterior bladder walls, the anterior and posterior vaginal fornices, the anterior two-thirds of the vaginal vault, urethra and both ureters. There is resultant hydroureter.

Potential adverse effects of Dendrite cell-based immunotherapy No dose-limiting toxicities were observed. No significant treatment- related toxicities were observed. Rare toxicities include pain at tumor sites approximately $24-48 \mathrm{~h}$ after receiving the vaccine, flu-like symptoms/ myalgia, fatigue, pruritis, injection site discomfort, and minimal pedal edema. Most common adverse effect observed in all cancer patients receiving DC therapy was fever, all patients recovered spontaneously or after antipyretic treatment with nonsteroid medicine. No other significant complications accompanying cell-based immunotherapy were observed. No clinical evidence of autoimmunity was observed in the patient population.
Effect of Vaccination on DC Induced T-Cell Proliferation

All patients underwent three doses of DC vaccination $\left(10 \mathrm{X} 10^{6}\right)$ after every 2 weeks' interval to assess their capacity to exhibit a primary immune response. PBMCs were isolated at serial time points. There is significant increase in the T-cell proliferation index after vaccination.

Effect of Vaccination on Tumor-Induced T-Cell Expression of IFN

To assess the effects of fusion cell vaccination on the capacity of patients to mount a tumor-specific CTL response, PBMCs were isolated at serial time points, cocultured with autologous tumor lysate, and analyzed for intracellular expression of IFN- by CD4 and CD8 T-cell populations. DC vaccine causes at least 30 to $40 \%$ increase in case of prostate cancer patients (Table 1, Figure 1) whereas it increases approximately 5 to $30 \%$ in case of breast cancer patients (Table 2, Figure 5); 40 to $97 \%$ increases in case of cervical patients (Table 3, Figure 7), the percentage of CD4 cells and CD8T cells expressing IFN-after tumor lysate exposure.

Table 1: Lymphocyte subset panel before and after each vaccination (Prostate Cancer)

\begin{tabular}{|l|c|c|c|c|}
\hline Lymphocytes & Before vaccination & \multicolumn{3}{|c|}{ After vaccination } \\
\hline Cell type & Dose 0 & Dose I & Dose II & Dose III \\
\hline Absolute CD3+ cells (cells/ul) & 145 & 187 & 143 & 145 \\
\hline Absolute CD4+ cells (cells/ul) & 104 & 142 & 122 & 113 \\
\hline Absolute CD8+ cells (cells/ul) & 40 & 52 & 35 & 34 \\
\hline Absolute NK cells CD16+CD56 (cells/ul) & 111 & 148 & 97 & 146 \\
\hline Absolute lymphocyte & 287 & 374 & 258 & 312 \\
\hline Helper/suppressor ratio & 2.60 & 2.75 & 3.50 & 3.36 \\
\hline
\end{tabular}

Table 2: Lymphocyte subset panel before and after each vaccination (Breast Cancer)

\begin{tabular}{|l|c|c|c|c|}
\hline Lymphocytes & Before vaccination & \multicolumn{3}{|c|}{ After vaccination } \\
\hline Cell type & Dose 0 & Dose I & Dose II & Dose III \\
\hline Absolute CD3+ cells (cells/ul) & NA & 1051 & 894 & 703 \\
\hline Absolute CD8+ cells (cells/ul) & 383 & 418 & 332 & 283 \\
\hline Absolute CD4+ cells (cells/ul) & 592 & 697 & 525 & 407 \\
\hline Total lymphocyte & 1230 & 1443 & 1249 & 930 \\
\hline Absolute lymphocyte & 287 & 374 & 258 & 312 \\
\hline Helper/suppressor ratio & 2.60 & 2.75 & 3.50 & 3.36 \\
\hline
\end{tabular}

Table 3: Lymphocyte subset panel before and after each vaccination (Cervical Cancer)

\begin{tabular}{|l|c|c|c|c|}
\hline Lymphocytes & Before vaccination & \multicolumn{3}{|c|}{ After vaccination } \\
\hline Cell type & Dose 0 & Dose I & Dose II & Dose III \\
\hline Absolute CD3+ cells (cells/ul) & 790 & 1278 & 818 & 1061 \\
\hline Absolute CD8+ cells (cells/ul) & 221 & 433 & 311 & 323 \\
\hline Absolute CD4+ cells (cells/ul) & 593 & 874 & 552 & 773 \\
\hline Total lymphocyte & 1267 & 1909 & 1290 & 1664 \\
\hline Absolute lymphocyte & 287 & 374 & 258 & 312 \\
\hline Helper/suppressor ratio & 2.60 & 2.75 & 3.50 & 3.36 \\
\hline
\end{tabular}



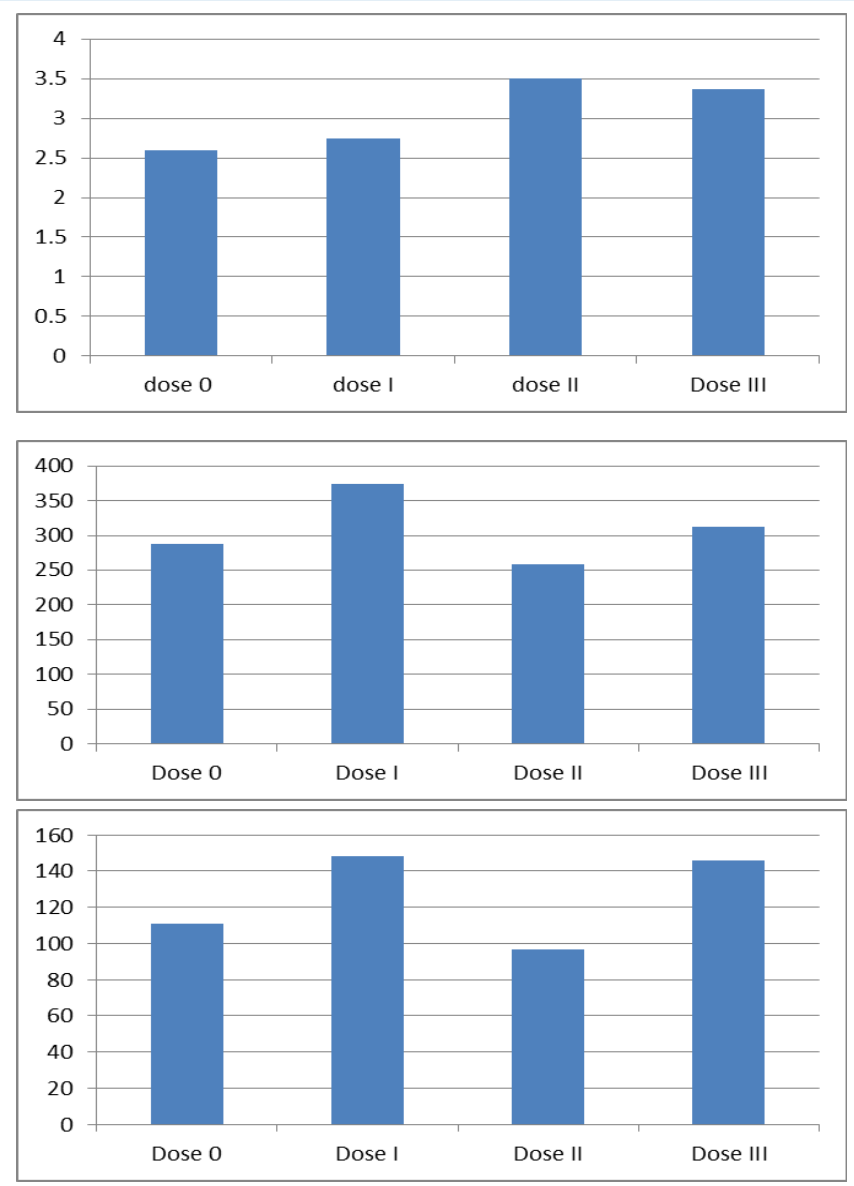

Figure 1: Variation in CD4:CD8 ratio, absolute lymphocyte and NK cells before and after

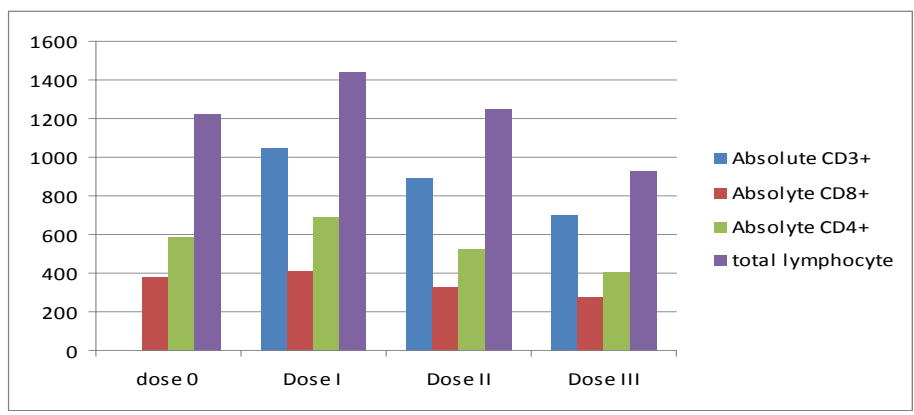

Figure 5: Variation in CD4:CD8 ratio, absolute lymphocyte before and after vaccination

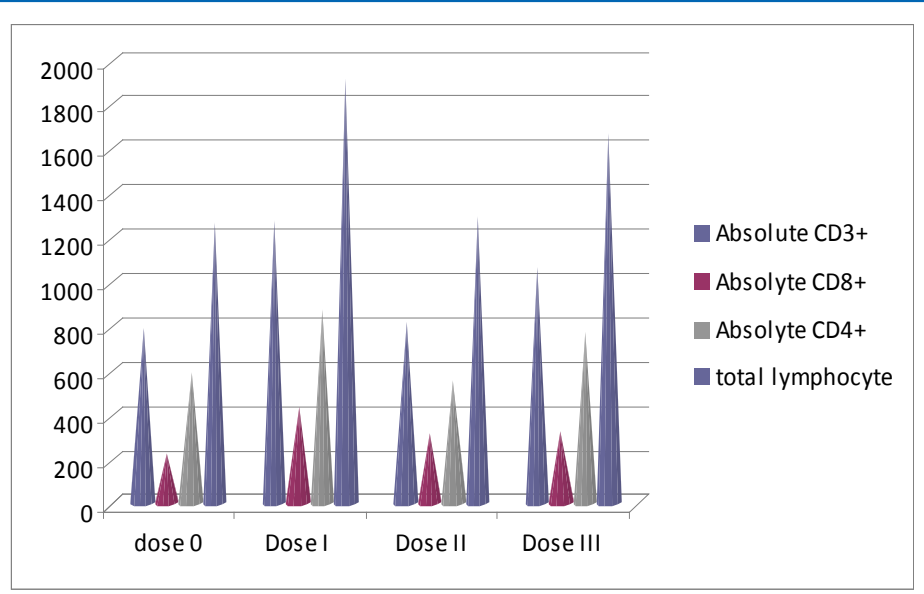

Figure 7: Variation in CD4:CD8 ratio, absolute lymphocyte cells before and after vaccination

\section{Clinical Responses}

Dendritic cell (vaccine) therapy was regularly monitored and tolerated well. No immediate or delayed adverse effects were observed. Liver function tests, kidney function tests, and analysis of hematological parameters revealed that they were in normal range. The period between any two vaccines remained uneventful. After 2 months of vaccine therapy, ultrasonography of the prostate, breast and cervical revealed normalcy in and around operation site.

In case of prostate cancer patient: Prior to the start of any procedure, the patient's PSA was $152.1 \mathrm{ng} / \mathrm{ml}$ and increased to $194.5 \mathrm{ng} / \mathrm{ml}$. However, once all doses were complete the PSA decreased to $44.13 \mathrm{ng} / \mathrm{ml}$. This was a remarkable finding of our study.

In ultrasound examination, we found prostate volume was 105.41 cc and after treatment it was measured as normal $16 \mathrm{cc}$, normal morphology of the urinary bladder and no mass, calculus or wall thickening observed. There was no evidence of adnexal mass, fluid collection or adenopathy (Figure 3 ).

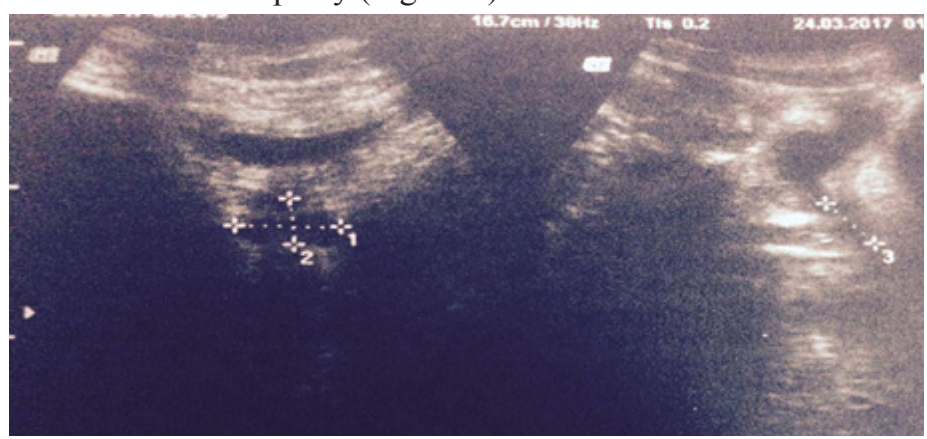

Figure 3: Post treatment changes in prostate (Ultrasound examination) 


\section{Post-Treatment}

At six months' post-treatment, the patient's PSA was $44.13 \mathrm{ng}$ / $\mathrm{ml}$ (Figure 2). Treatment was well tolerated and minimal side effects were reported, as the patient noted good urinary and bowel function following treatment.

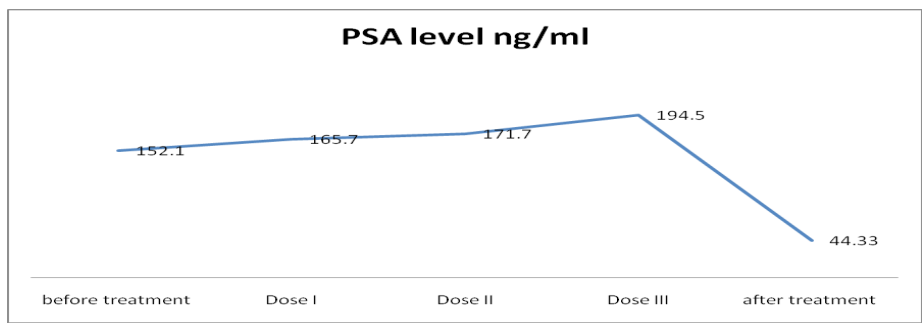

Figure 2: PSA level before and after treatment

In case of breast cancer patient: After vaccination, a breast cancer patient responded with near complete regression of a $3.57 \mathrm{~cm}$ $\mathrm{x} 3.89 \mathrm{~cm}$ chest wall mass in right breast, dilated ducts noted measuring $1.12 \mathrm{~cm}$, enlarged lymph nodes noted within right axilla, measuring $1.73 \mathrm{~cm}, 1.69 \mathrm{~cm}, 1.22 \mathrm{~cm}$ in diameter respectively (Figure 4) and no evidence of new disease at other sites. Whereas within left breast dilated ducts are seen, multiple lymph noted within left axilla but no discrete mass noted.
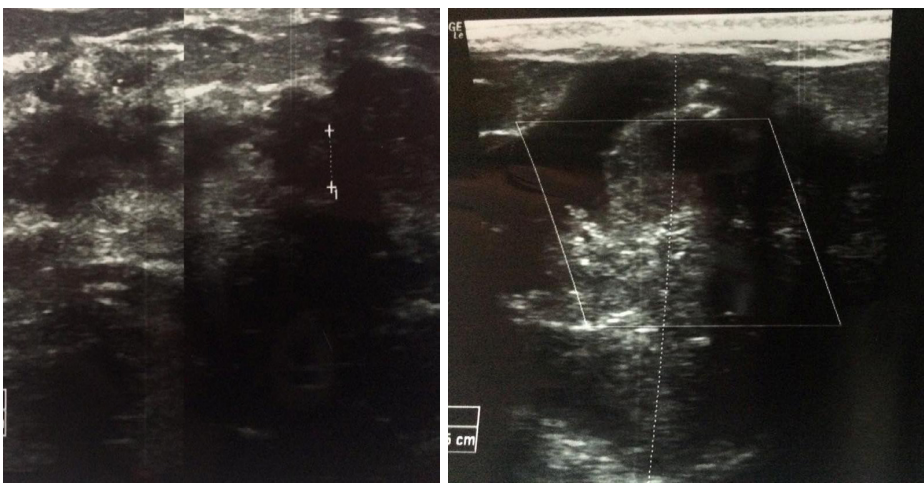

Figure 4: Clinical aspects of the disease. Right breast reveals a solid mass and an enlarged lymph node in the right axilla.

Her disease status remained stable with no evidence of progression until 6 th months after vaccination. Of note, this patient had a steady rise over time in the tumor-induced percentage of CD4 and CD8 T cells expressing intracellular IFN- (Figure 7). Expression of IFNby CD4 cells peaked after first dose vaccination at a level that was $20 \%$ increases as found before vaccination. The percentage of CD cells expressing IFN- peaked at first dose vaccination with a level $10 \%$ increases pre-vaccination. No other therapy was administered during this time.

In Case of Cervical Cancer Patients: Before start of treatment, there was severe in hydroneprosis and hydroureter, which was moderate after treatment. Increasing bilateral hydroneprosis and hydroureter secondary to the cervical mass. The uterus \& endometrium were also heterogeneous in appearance as before treatment. No evidence of bowel obstruction. Stable overall size of the cervical mass with MRI evidence of paracervical involvement as before. MRI features are suspicious for involvement of the posterior bladder wall and anterior rectal wall. A rectocervical fistula should also be excluded. No MRI evidence of abdominopelvic lymphadeopathy or metastic disease. Paraaortic and pelvic nodes appear within normal limits on MRI (Figure 6A and 6B). There was remarkable increase in CD4:CD8 ratio, absolute lymphocyte and NK cells. Mean values of lymphocyte count was increased which suggested that there was generation of tumor reactive cells CD4 and CD8 T cell surface molecules that play a role in $\mathrm{T}$ cell identification and activation by binding to their relevant major histocompatibility complex (MHC class I and II) ligands on dendritic cells. Antigen that bound to $\mathrm{MHC}$ class 1 molecule recognized by CD8+ T cells and antigen that bound to MHC class II molecule recognized by $\mathrm{CD} 4+\mathrm{T}$ cells that result in decrease in tumor burden.
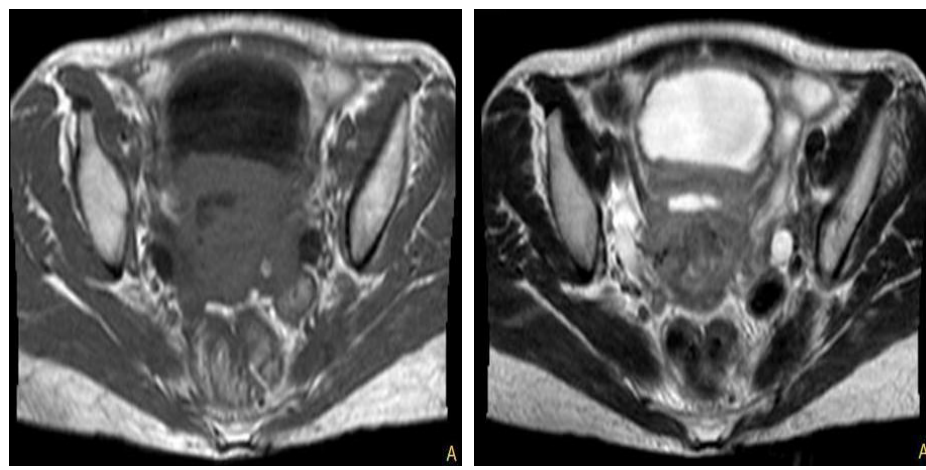

Figure 6 A: MRI scan of pelvis before treatment for cervical cancer Patient
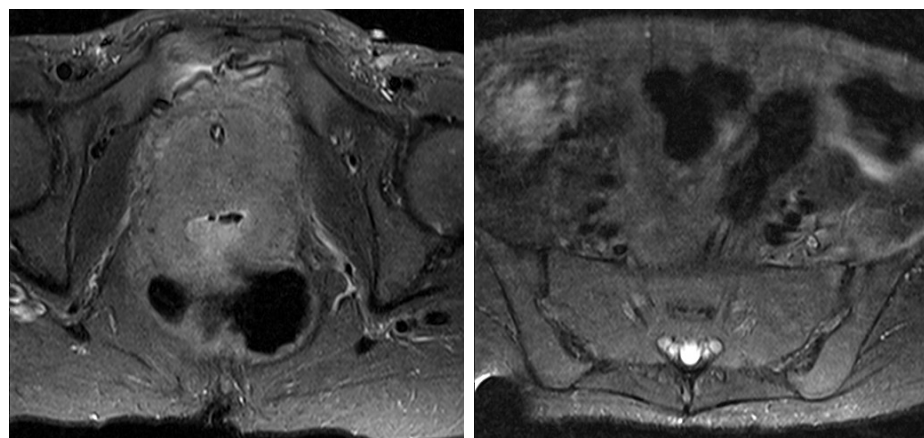

Figure 6 B: MRI scans of pelvis after treatment for cervical cancer Patient

\section{Discussion}

Cancer immunotherapy had shown a potential efficacy in tumor growth control and patient survival as the news released that "Instead of using surgery, chemotherapy, or radiotherapy, researchers from the National Institutes of Health are finding so far limited but inspiring success in a new approach for fighting cancer, using the immune system to attack the tumors the way it would be a cold or flu. -CNN.com (August 2006)" [14-16]. Although extensively studied in cells and animal models, the clinical data regarding the exact benefit of immunotherapy in patient survival and disease progression remain to be further investigated $[17,18]$. Despite limited size of cohorts, these case studies demonstrate a remarkable enhancement in the post-surgical control of tumor recurrence and survival rates in cancer patients treated with combined DC therapy. It has been well established that the DCs prime native T-cells and DC vaccine has achieved encouraging promise as a novel therapeutic approach for disease control in 
specific cancers [19]. DCs have the capability to present tumor antigens to $\mathrm{T}$ lymphocytes and induce the specific cytotoxic $\mathrm{T}$ cells against tumor antigens [20-23]. Sipuleucel-T, the first DC vaccine, was approved for clinical application by FDA in USA to treat asymptomatic metastatic castrate-resistant prostate cancer, improving patients' OS in phase III trial [14]. Additional promising results were reported in recent phase III trials using tumor vaccine to treat various late stage cancers, including melanoma, follicular lymphoma, CRC, and NSCLC. Studies in the clinics have established that DCs capture and process tumor-associated antigens and secrete cytokines to initiate an immune response [24, 25].

Clinical trials of DC vaccines have demonstrated minimal toxicity, evidence for the induction of tumor-specific cellular immunity, and, in certain patients, clinical response [26-31]. The use of whole cell approaches such as DC/tumor fusion allows for the presentation of multiple antigens, including those yet to be identified, in the context of DC-mediated co-stimulation. DC vaccine is shown to induce tumor-specific effector and memory T cells [32]. Therefore, the DC vaccine may have potential higher cytotoxic activity and specificity in the effector T cells, which shows both short and long term anti-tumor efficacy.

In the present case studies, patients with prostate, breast and cervical cancer were vaccinated with autologous tumor cells fused to autologous DCs. A concern was the feasibility of producing adequate fusion cell yields for vaccination from patient-derived specimens. DCs were generated in sufficient quantities and exhibited phenotypic and functional characteristics of partially mature DCs. The cells uniformly expressed class II and costimulatory molecules, but CD4, CD8 expression was modest and seen only in a subset of specimens. The major challenge for vaccine generation was obtaining an adequate yield of tumor cells.

In the present study, a subset of patients demonstrated evidence of immunological response to fusion cell vaccination by an increased percentage of $\mathrm{T}$ cells expressing intracellular IFN- after ex vivo exposure to tumor lysate. The correlation between in vitro immunological assays and clinical response is not well defined. In one study, immunological response to at least two antigens after vaccination with DCs loaded with multiple peptides was associated with clinical outcome [28]. In our study, disease regression in response to vaccination was associated with increased tumor lysate-induced IFN__ expression. In one patient with an immune response, vaccination resulted in the near complete regression of a large chest wall mass. Of note, autoimmunity is a potential concern when using whole cell vaccine approaches in which tumorassociated antigens are introduced with shared self-antigens. In the present study, vaccination was well tolerated, and there was no evidence of clinically significant autoimmunity. DC-based vaccine studies have demonstrated encouraging results; however, issues remain regarding the optimal approach.

One issue is whether autologous or allogeneic DCs are more effective as fusion partners. DCs isolated from cancer patients can exhibit an impaired capacity to express co-stimulatory molecules [33]. However, functional deficiencies observed in DCs isolated from cancer patients are not generally seen in DCs generated by ex vivo culture of progenitors with cytokines $[34,35]$. Fusions generated with allogeneic DCs are dependent on tumor cell expression of class I molecules for antigen presentation. In this regard, loss of class I expression has been demonstrated in tumor cells as a potential mechanism for evasion of host immunity [36]. Immune response after DC vaccination is also determined, in part, by the stage of DC maturation [37]. Immature DCs secrete IL-10 and bias responding $T$ cells toward a T helper 2 phenotype $[38,39]$. By contrast, mature DCs secrete IL-12 and are potent inducers of T helper 1-mediated cytotoxicity [40, 41]. Moreover, with fusion cells, production of IL-10 by the tumor could potentially inhibit DC maturation and function [42-44]. The use of cytokine adjuvant may thus augment effectiveness of the fusion cell vaccine. IL-12 is a heterodimeric cytokine that up-regulates DC expression of costimulatory molecules, stimulates $\mathrm{T}$ helper 1 reactivity, expands antigen-specific CD8 T cells, and enhances the effectiveness of DC-based antitumor vaccines [45-49]. Moreover, administration of IL-12 with DC fusion cells has substantially improved induction of antitumor immunity in animal tumor models of intracranial glioma and multiple myeloma $[50,51]$. Thus, administration of IL-12 could potentiate the effectiveness of the fusion cell vaccine in cancer patients.

In agreement with the clinical benefits observed in other clinical trials, our studies suggest that DC treatment can significantly enhance patient survival, prompting its future clinical investigation [52]. Although a number of CD4, CD3 \& CD8 were elevated in the DC, only CD4, CD3 \& CD8 showed a significant increase in patients' sera in our studies. Studies demonstrated that CD4, CD3 \& CD8 play critical roles in immunotherapy using DC [53, 54]. Tumor cells are highly heterogeneous and a specific tumor may contain cells with both high and low MHC-I populations [55-57]. Interestingly, MHC-I expression shows heterogeneous among tumor cells and radiation promotes the immunological recognition of the tumor cells by immune cells via MHC-I [58]. However, probably due to the heterogeneity in a given tumor, a single type of immune therapy may only be effective in a subpopulation of cancer patients. Similarly, tumor cells with higher MHC-I expression may be more sensitive to DC vaccine therapy. As discussed earlier through this treatment, it led to increase in CD4:CD8 ratio, absolute lymphocyte and NK cells, which ultimately decrease in tumor burden.

Based on the present results, which demonstrate the induction of immunological and clinical antitumor activity, and the potential for improving these responses, clinical trials are under way to identify a more effective strategy for fusion cell vaccination. These trials will define the toxicity, immunological responses, and clinical efficacy of fusions with mature autologous or allogeneic DCs and vaccination in the context of adjuvant IL-12 or GM-CSF.

Future trials will need to be performed comparing newer treatments with those more established chemotherapy regimens. With these issues in focus, dendritic cell therapy seems to have significant promise as a treatment modality where no effective treatment previously existed.

The study has some limitations; the enrolled patients were in the advanced stage of cancer. Only three doses were given to the 
patients. Randomized clinical trial will be performed with various combination of dendritic cell therapy along with $\mathrm{T}$ cells therapy. One or more trials in large number of subjects with active and placebo control will increase the validity of the above study.

\section{Future Direction}

Combination Approach for Effective Antitumor Response (T cell therapy): Effective antitumor responses in patients with malignancies depend on the presence and function of immune cells that can recognize and eliminate tumor cells [59-62]. Among the immune cells, DCs are the antigen presenting cells (APCs) that play major role in activating the immune system against cancer cells. The application of ex vivo generated DCs emerged in an effort to improve the therapeutic efficacy in cancer patients with dysfunctional endogenous DCs. In the last decade, a large number of clinical trials were carried out to establish the therapeutic efficacy of DC vaccines. Among the over 200 DC based clinical trials so far, melanoma was the most common cancer treated which established the feasibility and safety of DC vaccines [63].

The advantages of the DC vaccines include low toxicity (grade 3 and 4 level toxicities are rare), less possibilities of immunotherapy induced autoimmunity, and induction of immunogenicity even in advanced malignancies $[64,65]$. On the other hand, there is still a lot to improve in the clinical efficacy. One approach to achieve that is the combinatorial therapy of DC Vaccines and TILs. Park et al (2007) carried out preclinical studies on murine colorectal tumor by combining the two immunotherapeutic approaches [66]. The results demonstrated that $\mathrm{T}$ cell transfer and $\mathrm{DC}$ vaccination could induce a potent antitumor response. This strategy dramatically increased $\mathrm{T}$ cells in lungs and spleen, resulting in prolonged survival. In another melanoma murine model study, injection of $\mathrm{DC}$ vaccine along with adoptively transferred $\mathrm{T}$ cells improved the antitumor response in comparison to either treatment alone [67]. Moreover, the vaccination combination (DC and TILs) led to tumor regression and provided protection against tumor re-challenges. Kandalaft et al (2013) showed dendritic cell vaccination with bevacizumab and metronomic cyclophosphamide, followed by autologous adoptive T-cell therapy was practicable and well tolerated [68].

Synergistic Effect of DC and Chemotherapy: Tumor induced immune suppression is caused by $\mathrm{T}$ regulatory cells (Treg cells) making dendritic cells tolerogenic. Chemotherapeutic drugs inhibit Treg induced suppression by blocking activity of Treg cells. Chemotherapeutic drugs indicated here can cause direct stimulation of $\mathrm{T}$ effector and NK cells that can lead to anti-tumor activity. Chemo drugs by their virtue of cytotoxic function leads to immonogenic cancer cell death thereby enhancing immunovisibility of tumor debri favoring phagocytosis by dendritic cells [69].

Hence, it leads effective combination of DC activated cytokine induced killer cells CIKs along with chemotherapy enhanced antitumor activity via up regulation of anti-tumor cytokines including IFN- $\gamma$, TNF- $\alpha$, TNF- $\beta$ and MIG $[70,71]$.

Future Directions in Cancer Vaccine Development

The current studies demonstrate the potential of autologous DC as a vehicle to deliver specific target antigen, a crucial issue in cancer vaccine development. In our future case study, we hope to expand the antigen repertoire of our vaccine study from two PSMA peptides (each of which represents nine amino acids) to a recombinant PSMA protein consisting of the native sequence without the transmembrane domain. This change will multiply the number of targets for T cell attack, and thus produce a potentially more effective vaccine.

\section{Conclusion}

We conclude that dendritic cell therapy is a safe and well tolerated immunotherapeutic method that can elicit immunity even in patients with advanced-stage cancer. This work also confirms that dendritic cell-based interventions have only some capacity to produce objective tumour responses. Although not all studies were designed primarily to measure survival, an increasing number indicate that dendritic cell therapy could confer a survival benefit. These preliminary but encouraging survival data provide a strong incentive to begin a new series of clinical trials using overall survival as the primary endpoint. The rational use of these vaccines in combination with other anticancer therapies that could improve their effectiveness. These developments might hold the key to the full therapeutic potential of dendritic cells for cancer immunotherapy.

\section{References}

1. Steinman RM (1991) The dendritic cell system and its role in immunogenicity. Annu Rev Immunol 9: 271-296.

2. Austyn JM (1996) New insights into the mobilization and phagocytic activity of dendritic cells. J Exp Med 1996; 183:1287-1292.

3. Hsu FJ, Benike C, Fagnoni F (1996) Vaccination of patients with B-cell lymphoma using autologous antigen- pulsed dendritic cells. Nat Med 2: 52-58.

4. Mukherji B, Chakraborty NG, Yamasaki S (1995) Induction of antigen-specific cytolytic $\mathrm{T}$ cells in situ in human melanoma by immunization with synthetic peptide- pulsed autologous antigen presenting cells. Proc Natl Acad Sci USA 92: 80788082.

5. Nestle FO, Alijagic S, Gilliet M (1998) Vaccination of melanoma patients with peptide- or tumor lysatepulsed dendritic cells. Nat Med 4: 328-332.

6. Mellman I, Steinman RM (2001) Dendritic cells: specialized and regulated antigen processing machines. Cell 106: 255258.

7. Heath WR, Carbone FR (2001) Cross-presentation, dendritic cells, tolerance and immunity. Annu Rev Immunol 19: 47-64.

8. Dubsky P, Ueno H, Piqueras B, Connolly J, Banchereau J, Palucka AK (2005) Human dendritic cell subsets for vaccination. J Clin Immunol 25: 551-572.

9. Dees EC, McKinnon KP, Kuhns JJ, Chwastiak KA, Sparks S, et al. (2004) Dendritic cells can be rapidly expanded ex vivo and safely administered in patients with metastatic breast cancer. Cancer Immunol Immunother 53: 777-785.

10. Landis SH, Murray T, Bolden S, Wingo PA (1999) Cancer statistics, 1999. CA Cancer J Clin 49: 8-31.

11. Jones GW, Mettlin C, Murphy GP (1995) Patterns of care for carcinoma of the prostate gland: Results of a national survey of 1984 and 1990. J Am Coll Surg 180: 545-554.

12. Aristóteles Rosmaninho (2012) Glória Velho, Mónica Caetano, Manuela Selores. Breast cancer: 2 case reports. An 
Bras Dermatol 87: 123-126.

13. Dunne EF, Unger ER, Sternberg M, McQuillan G, Swan DC, et al. (2007) Prevalence of HPV infection among females in the United States. Jama 297: 813-819.

14. Kantoff PW, Higano CS, Shore ND, Berger ER, Small EJ, el al. (2010) Sipuleucel-T immunotherapy for castrationresistant prostate cancer. N Engl J Med 363: 411-422.

15. Morse MA, Deng Y, Coleman D, Hull S, Kitrell-Fisher E, et al. (1999) A Phase I study of active immunotherapy with carcinoembryonic antigen peptide (CAP-1)-pulsed, autologous human cultured dendritic cells in patients with metastatic malignancies expressing carcinoembryonic antigen. Clin Cancer Res 5: 1331-1338.

16. O'Neill D, Bhardwaj N (2005) Exploiting dendritic cells for active immunotherapy of cancer and chronic infection. Methods Mol Med 109: 1-18.

17. Frohlich MW (2012) Sipuleucel-T for the treatment of advanced prostate cancer. Semin Oncol 39: 245-252.

18. Madan RA, Schwaab T, Gulley JL (2012) Strategies for optimizing the clinical impact of immunotherapeutic agents such as sipuleucel-T in prostate cancer. J Natl Compr Canc Netw 10: 1505-512.

19. O'Neill DW, Bhardwaj N (2007) Exploiting dendritic cells for active immunotherapy of cancer and chronic infections. Mol Biotechnol 36: 131-141.

20. Steinman RM, Banchereau J (2007) Taking dendritic cells into medicine. Nature 449: 419-426.

21. Melief CJ (2007) Cancer: immune pact with the enemy. Nature 450: 803-804.

22. Banchereau J, Steinman RM (1998) Dendritic cells and the control of immunity. Nature 392: 245-252.

23. van Broekhoven CL, Parish CR, Demangel C, Britton WJ, Altin JG (2004) Targeting dendritic cells with antigen-containing liposomes: a highly effective procedure for induction of antitumor immunity and for tumor immunotherapy. Cancer Res 64: 4357-4365.

24. Schlom J (2012) Recent advances in therapeutic cancer vaccines. Cancer Biother Radiopharm 27: 2-5.

25. Marten A, Ziske C, Schottker B, Renoth S, Weineck S, et al. (2001) Interactions between dendritic cells and cytokineinduced killer cells lead to an activation of both populations. J Immunother 24: 502-510.

26. Nair SK, Morse M, Boczkowski D (2002) Induction of tumorspecific cytotoxic $\mathrm{T}$ lymphocytes in cancer patients by autologous tumor RNA-transfected dendritic cells. Ann Surg 235: 540-549.

27. Nestle FO, Alijagic S, Gilliet M (1998) Vaccination of melanoma patients with peptide- or tumor lysate-pulsed dendritic cells. Nat Med 4: 328-332.

28. Banchereau J, Palucka AK, Dhodapkar M (2001) Immune and clinical responses in patients with metastatic melanoma to $\mathrm{CD} 34\left(\_\right.$) progenitor-derived dendritic cell vaccine. Cancer Res 61: 6451-6458.

29. Timmerman JM, Czerwinski DK, Davis TA (2002) Idiotypepulsed dendritic cell vaccination for B-cell lymphoma: clinical and immune responses in 35 patients. Blood 99: 1517-1526.

30. Schuler-Thurner B, Schultz ES, Berger TG (2002) Rapid induction of tumor-specific type $1 \mathrm{~T}$ helper cells in metastatic melanoma patients by vaccination with mature, cryopreserved, peptide-loaded monocytederived dendritic cells. J Exp Med 195: 1279-1288.

31. Geiger JD, Hutchinson RJ, Hohenkirk LF (2001) Vaccination of pediatric solid tumor patients with tumor lysate-pulsed dendritic cells can expand specific T cells and mediate tumor regression. Cancer Res 61: 8513-8519.

32. Thanendrarajan S, Nowak $M$, Abken $H$, Schmidt-Wolf IG (2011) Combining cytokine-induced killer cells with vaccination in cancer immunotherapy: more than one plus one? Leuk Res 35: 1136-1142.

33. Brown RD, Pope B, Murray A (2001) Dendritic cells from patients with myeloma are numerically normal but functionally defective as they fail to up-regulate CD80 (B7-1) expression after huCD40LT stimulation because of inhibition by transforming growth factor-beta1 and interleukin- 10 . Blood 98: 2992-2998.

34. Avigan $\mathrm{D}, \mathrm{Wu} \mathrm{Z}$, Joyce R (2000) Immune reconstitution following high-dose chemotherapy with stem cell rescue in patients with advanced breast cancer. Bone Marrow Transplant 26: 169-176.

35. Raje N, Gong J, Chauhan D (1999) Bone marrow and peripheral blood dendritic cells from patients with multiple myeloma are phenotypically and functionally normal despite the detection of Kaposi's sarcoma herpesvirus gene sequences. Blood 93: 1487-1495.

36. Luboldt H, Kubens B, Rubben H, Grosse-Wilde H (1996) Selective loss of human leukocyte antigen class I allele expression in advanced renal cell carcinoma. Cancer Res 56: 826-830.

37. Dhodapkar MV, Steinman RM, Krasovsky J, Munz C, Bhardwaj N (2001) Antigen-specific inhibition of effector T cell function in humans after injection of immature dendritic cells. J Exp ed 193: 233-238.

38. De Smedt T, Van Mechelen M, De Becker G (1997) Effect of interleukin-10 on dendritic cell maturation and function. Eur $\mathrm{J}$ Immunol 27: 1229-1235.

39. Corinti S, Albanesi C, Sala A, Pastore S, Girolomoni G (2001) Regulatory activity of autocrine IL-10 on dendritic cell functions. J Immunol 166: 4312-438.

40. Ebner S, Ratzinger G, Krosbacher B (2001) Production of IL-12 by human monocyte-derived dendritic cells is optimal when the stimulus is given at the onset of maturation, and is further enhanced by IL-4. J Immunol 166: 633-641.

41. Banchereau J, Briere F, Caux C (2000) Immunobiology of dendritic cells. Annu Rev Immunol 18: 767-811.

42. Steinbrink K, Graulich E, Kubsch S, Knop J, Enk AH (2002) CD4( () and $\mathrm{CD} 8\left(\_\right)$anergic T cells induced by interleukin10-treated human dendritic cells display antigen-specific suppressor activity. Blood 99: 2468-2476.

43. Yang AS, Lattime EC (2003) Tumor-induced interleukin 10 suppresses the ability of splenic dendritic cells to stimulate CD4 and CD8 T-cell responses. Cancer Res 63: 2150-2157.

44. Kiertscher SM, Luo J, Dubinett SM, Roth MD (2000) Tumors promote altered maturation and early apoptosis of monocytederived dendritic cells. J Immunol 164: 1269-1276.

45. Lamont AG, Adorini L (1996) IL-12: a key cytokine in immune regulation. Immunol Today 17: 214-217.

46. Lehmann A, Adorini L (2001) Activation of natural killer cells withinterleukin 2 (IL-2) and IL-12 increases perforin binding 
and subsequent lysis of tumor cells. Br J Haematol 114: 660665.

47. Grohmann U, Bianchi R, Ayroldi E (1997) A tumor- associated and self antigen peptide presented by dendritic cells may induce $\mathrm{T}$ cell anergy in vivo, but IL-12 can prevent or revert the anergic state. J Immunol 158: 3593-3602.

48. Koido S, Kashiwaba M, Chen D, Gendler S, Kufe D (2000) Induction of antitumor immunity by vaccination of dendritic cells transfected with MUC1 RNA. J Immunol 165: 57135719.

49. Gabrilovich D, Cunningham H, Carbone D (1996) IL-12 and mutant p53 peptide-pulsed dendritic cells for the specific immunotherapy of cancer. J Immunother Emphasis Tumor Immunol 19: 414-418.

50. Akasaki Y, Kikuchi T, Homma S (2000) Antitumor effect of immunizations with fusions of dendritic and glioma cells in a mouse brain tumor model. J Immunother 24: 106-113.

51. Gong J, Koido S, Chen D (2002) Immunization against murine multiple myeloma with fusions of dendritic and plasmacytoma cells is potentiated by interleukin 12. Blood 99: 2512-2517.

52. Schlom J (2012) Recent advances in therapeutic cancer vaccines. Cancer Biother Radiopharm 27: 2-5.

53. Marten A, Ziske C, Schottker B, Weineck S, Renoth S, et al. (2001) Transfection of dendritic cells (DCs) with the CIITA gene: increase in immunostimulatory activity of DCs. Cancer Gene Ther 8: 211-219.

54. Li H, Wang C, Yu J, Cao S, Wei F, et al. (2009) Dendritic cell-activated cytokine-induced killer cells enhance the antitumor effect of chemotherapy on non-small cell lung cancer in patients after surgery. Cytotherapy 11: 1076-1083.

55. Duru N, Fan M, Candas D, Menaa C, Liu HC, et al. (2012) HER2-associated radioresistance of breast cancer stem cells isolated from HER2-negative breast cancer cells. Clin Cancer Res 18: 6634-6647.

56. Li CD, Zhang WY, Li HL, Jiang XX, Zhang Y, et al. (2005) Mesenchymal stem cells derived from human placenta suppress allogeneic umbilical cord blood lymphocyte proliferation. Cell Res 15: 539-547.

57. Beutler N, Hauka S, Niepel A, Kowalewski DJ, Uhlmann J, et al. (2013) A natural tapasin isoform lacking exon 3 modifies peptide loading complex function. Eur J Immunol 43: 14591469.

58. Sharma A, Bode B, Wenger RH, Lehmann K, Sartori AA, et al. (2011) Gamma-Radiation promotes immunological recognition of cancer cells through increased expression of cancer-testis antigens in vitro and in vivo. PLoS One 6: e28217.

59. Woo EY, Chu CS, Goletz TJ, Schwinger K, Yeh H, et al. (2001) Regulatory CD4 (+) CD25 (+) T cells in tumors from patients with early-stage non-small cell lung cancer and latestage ovarian cancer. Cancer Res 61: 4766-4772.
60. Javia LR, Rosenberg SA (2003) CD4+CD25+ suppressor lymphocytes in the circulation of patients immunized against melanoma antigens. J Immunother 26: 85-93.

61. Marshall NA, Christie LE, Munro LR, Culligan DJ, Johnston PW, et al. (2004) Immunosuppressive regulatory T cells are abundant in the reactive lymphocytes of Hodgkin lymphoma. Blood 103: 1755-1762.

62. Andaloussi AE, Lesniak SM (2006) An increase in CD4+CD25+FOXP3+ regulatory T cells in tumor-infiltrating lymphocytes of human glioblastoma multiforme. NeuroOncology 8: 234-243.

63. Mahmood A, Rajasekar S, Bora C, Andrali SS (2015) Synergistic Effect of Dendritic Cell Vaccine with Immune Modulating Chemo Drugs. Journal of Academia and Industrial Research (JAIR) 3: 500-597.

64. Marroquin CE, Westwood JA, Lapointe R, Mixon A, Wunderlich JR, et al. (2002) Mobilization of dendritic cell precursors in patients with cancer by flt 3 ligand allows the generation of higher yields of cultured dendritic cells. J Immunother 25: 278-288.

65. Michels T, Shurin GV, Naiditch H, Sevko A, Umansky V, et al. (2012) Paclitaxel promote differentiation of myeloidderived suppressor cells into dendritic cells in vitro in a TLR4independent manner. Immunotoxicol 9: 292-300.

66. Park MY, Kima CM, Hyun H, Sohn HJ, Oh S, et al. (2007) The optimal interval for dendritic cell vaccination following adoptive $\mathrm{T}$ cell transfer is important for boosting potent antitumor immunity. Vaccine 25: 7322-7330.

67. Song S, Zhang K, You H, Wang J, Wang Z, et al (2010) Significant anti-tumour activity of adoptively transferred $T$ cells elicited by intratumoral dendritic cell vaccine injection through enhancing the ratio of CD8 $+\mathrm{T}$ cell/regulatory T cells in tumour. Clinical and Experimental Immunology 162: 7583.

68. Kandalaft LE, Powell DJ, Chiang CL, Tanyi J, et al. (2013) Autologous lysate-pulsed dendritic cell vaccination followed by adoptive transfer of vaccine-primed ex vivo co-stimulated $\mathrm{T}$ cells in recurrent ovarian cancer. OncoImmunology 2: e22664.

69. Anjum Mahmood, Seetharaman Rajasekar, Chandan Bora, Shiva Sreenath Andrali (2015) Synergistic Effect of Dendritic Cell Vaccine with Immune Modulating Chemo Drugs. Journal of Academia and Industrial Research (JAIR) 3: 590-597.

70. Li H, Wang C, Yu J, Cao S, Wei F, et al. (2009) Dendritic cell-activated cytokine-induced killer cells enhance the antitumor effect of chemotherapy on non-small cell lung cancer in patients after surgery. Cytotherapy 11: 1076-1083.

71. Yang L, Ren B, Li H, Yu J, Cao S, et al. (2013) Enhanced antitumor effects of DC-activated CIKs to chemotherapy treatment in a single cohort of advanced non-small-cell lung cancer patients. Cancer Immunol. Immunother 62: 65-73.
Copyright: (C2021 Pramod S Dhembare, et al. This is an open-access article distributed under the terms of the Creative Commons Attribution License, which permits unrestricted use, distribution, and reproduction in any medium, provided the original author and source are credited. 